\section{YOUNG SCIENTIST}

\section{Paying the rent}

A plan to phase out housing subsidies for postdocs at Rockefeller University in New York has been put on hold. Suggested in July, the move would have slowly reduced a $15 \%$ rent subsidy to zero.

The proposal was put forward long before new university president Paul Nurse was due to take up his post full-time; and when the university's postdoctoral association learned of the plan, it mounted a concerted effort to tell him what the financial impact of the cut would be. The subsidy, it said, was what made it possible for postdocs surviving on a stipend to afford to live in New York.

Reacting to the postdocs' concerns, Nurse has suspended any changes pending a comprehensive review of the entire postdoc remuneration package, including salary, housing, health benefits and day care - all issues raised in a recent survey that was commissioned by the postdoctoral association.

The challenge now is for the whole Rockefeller community to work together to resolve this situation. But if the tone of the welcoming party held by the postdoctoral association for the new president is any indication, Rockefeller postdocs can confidently look forward to a fruitful existence under his guidance.

The Rockefeller University Postdoctoral Association

1) www.rockefeller.edu/pda
$\mathrm{D}$ ale Carnegie, who wrote the bestselling book How to Win Friends and Influence People, asserts that you can make more contacts in two months by becoming interested in others' work than by spending two years trying to get them interested in yours.

But how can this help your science career? Simple. Developing a network of mutually beneficial contacts can ease any of your career challenges - from changing job, to securing a grant or getting a promotion recommendation.

Networking is a giveand-take process that requires a genuine interest in and focus on others. It is not limited to the staged and formal gatherings of experts; it happens naturally all the time. Everyone, even a social acquaintance outside your profession, is a potential resource who may know someone or something that will prove useful to your

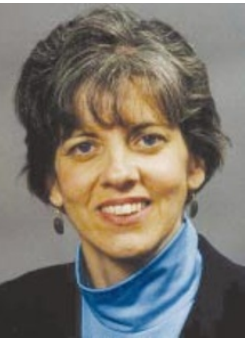

With Deb Koen Careers consultant

career. Move beyond your usual sphere of influence to diversify your network of people and ideas. Start with a fairly comfortable venue and progress to more personally challenging situations.

To ease into first-time conversations, develop a three-part introduction that includes your name, your speciality or focus, and an interesting point of distinction. If you can get past the introduction and are a good listener, you'll be ready on any occasion with a flowing response to the recurring question: "So, what do you do?" If you are seeking assistance beyond the introduction, be concise and specific in your request. Get to the point, be considerate of time, and listen as much as you speak.

Remember, you need to add value as well as make requests. So consider the support, information and resources that you can contribute. Help others by reviewing manuscripts for journals, serving on study sections for granting bodies, taking part in professional associations, speaking on alumni panels, adopting a collaborative approach at work and sharing credit with those who have helped you.

Networking is a vital force in both getting work and getting work done. To enjoy the benefits, steer clear of the 'me, me, me' mindset and focus on what you can do for others.

Deb Koen is vice-president of Career Development Services, a national career-management firm, and is a columnist for The Wall Street Journal's CareerJournal.com.

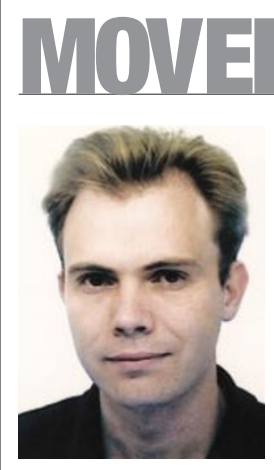

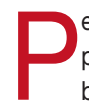
er Ahlberg's career as a palaeontologist has been marked by a constant search for balance - between teaching and research, his professional and personal life, and his native Sweden and his adopted home in England. His new position at Uppsala University, he says, brings all of those elements into line.

After earning his $\mathrm{PhD}$ in 1989, Ahlberg took up a post, the title of which is now extinct - he became a 'departmental demonstrator' at the University of Oxford. That meant a fixed-term contract, with a heavy load of supervising practical lab classes and individual tutorials. Looking

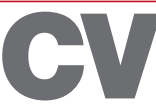

1994-2003: Researcher (fossil fish and amphibians), palaeontology department, Natural History Museum, London

1989-1994: Departmental demonstrator (vertebrate biology), zoology department, University of Oxford 1989: PhD in Zoology, University of Cambridge back, Ahlberg feels that the mix of teaching and research stood him in good stead. But at the time, he was worried that the position would shackle him professionally, as his teaching commitments meant he couldn't take on the kind of research that can make or break a palaeontologist's career.

Ahlberg used a combination of fortune, experience, knowledge and instinct to turn this disadvantage on its head. Because he had little time or budget for travel, he devoted much of his non-teaching time to combing through collections in museums. At one museum, he noticed that some fossils that had been classified as bony-fish fragments in the nineteenth century actually had features, such as a distinctive snout, associated with landbased vertebrates, or tetrapods, that he had collected on a postgraduate dig in Greenland. Ahlberg showed that the mislabelled bony fish was actually the oldest known fossil of a tetrapod. The discovery served as a springboard for his scientific career and reinforced his inclination never to accept conventional wisdom.

A series of related findings led to a post at London's Natural History Museum. But after nearly a decade, the pendulum had swung too far in the other direction. He had plenty of time for research and travel, but was missing teaching. "I like the contact with the undergrads," Ahlberg says. And the 90-minute journey to work in central London took a toll, particularly after the birth of his daughter in 2001.

The Uppsala appointment resolves all those issues, he says. He has the right teaching load now, and the office is a five-minute bike ride from home. Ahlberg sums up his career with a simple statement: "I was able to recognize some things that hadn't been recognized." The same might be said for his recognition of the need for balance. 